\title{
Comparative Plasma Exposure of Albendazole after Administration of Rapidly Disintegrating Tablets in Dogs
}

\author{
Silvina G. Castro, ${ }^{1,2}$ Alicia Dib, ${ }^{3}$ Gonzalo Suarez, ${ }^{3}$ Daniel Allemandi, ${ }^{1,2}$ Carlos Lanusse, ${ }^{2,4}$ \\ Sergio Sanchez Bruni, ${ }^{2,4}$ and Santiago D. Palma ${ }^{1,2}$ \\ ${ }^{1}$ Department of Pharmacy, Faculty of Chemical Sciences, UNITEFA, Universidad Nacional de Córdoba, 5000 Córdoba, Argentina \\ ${ }^{2}$ Consejo Nacional de Investigaciones Científicas y Técnicas-CONICET, Argentina \\ ${ }^{3}$ Laboratory of Pharmacology, Faculty of Veterinary Medicine, Universidad de la Republica, 11600 Montevideo, Uruguay \\ ${ }^{4}$ Laboratory of Pharmacology, Faculty of Veterinary Medicine, CIVETAN-UNCPBA, 7000 Tandil, Argentina
}

Correspondence should be addressed to Santiago D. Palma; sdpalma@gmail.com

Received 25 April 2013; Revised 4 July 2013; Accepted 15 July 2013

Academic Editor: Xin Ming

Copyright (C) 2013 Silvina G. Castro et al. This is an open access article distributed under the Creative Commons Attribution License, which permits unrestricted use, distribution, and reproduction in any medium, provided the original work is properly cited.

\begin{abstract}
The main objectives of this study were (a) to evaluate the in vitro performance of the rapid disintegration tablets as a way to improve the solid dispersions and (b) to study the in vivo pharmacokinetics of the albendazole modified formulation in dogs. Rapid disintegration of tablets seems to be a key factor for efficiency of solid dispersions with regard to improvement of the albendazole bioavailability. The in vivo assays performed on dogs showed a marked increase in drug plasma exposure when albendazole was given in solid dispersions incorporated into rapid disintegration tablets compared with conventional solid dosage form.
\end{abstract}

\section{Introduction}

Benzimidazoles (BZD) form a family of related anthelmintic compounds and their metabolites/derivatives, which are widely used in antiparasite therapy in both veterinary and human medicine.

The parent drugs, febendazole (FBZ) and albendazole (ABZ), contain a sulphur atom as a sulphide at position 5 of the BZD molecule. These sulphides are subjected, mainly in the liver, to phase I reactions (oxidation), catalysed by the flavin monooxygenase (FMO) and the cytochrome P-450 (Cyt P-450) enzyme systems to form sulfoxide (SO) metabolites, with FBZSO (oxfendazole; OFZ) and ABZSO being the primary, pharmacologically active metabolites generated [1, 2]. In a second metabolic reaction (sulphonation), catalysed by the Cyt P-450 system OFZ and ABZSO are transformed into inactive sulphone $\left(\mathrm{SO}_{2}\right)$ metabolites, namely, $\mathrm{FBZSO}_{2}$ and $\mathrm{ABZSO}_{2}$, respectively [2].

Several studies have suggested that only limited rates of dissolution and absorption of BZD anthelmintics are achieved in cat, dog, and human. Consequently, these compounds may need to be given at higher doses or as multiple administrations in order to provide adequate therapeutic concentrations to give an acceptable anthelmintic efficacy [35]. Therefore, new pharmaceutical alternatives are necessary for increasing the BZD drug exposure to shorten the multiple administrations. According to the biopharmaceutical classification system (BCS), ABZ is a BCS class II compound [6] with an aqueous solubility of less than $5 \mu \mathrm{g} / \mathrm{mL}$ and many investigations have suggested that dissolution of $\mathrm{ABZ}$ is the rate-limiting step for its absorption [7]. It is thus desirable to enhance the dissolution rate of the drug in order to increase its rate of absorption.

The rate at which a solid dissolves is directly proportional to the surface area of drug exposed to the dissolution medium and is given by the Noyes-Whitney equation [8].

Solid dispersions (SDs), which are defined as molecular mixtures of poor water-soluble drugs and hydrophilic carriers, have been proposed as alternatives for improving the dissolution rate of these kinds of drugs [9], with ABZ dissolution having previously been assayed at our laboratory using solid dispersions (SDs) with poloxamer 188 (P 188) as carrier. Although the proportion of $\mathrm{P} 188$ incorporated in SDs had a marked influence on ABZ release during the initial 
stage ( $5 \mathrm{~min}$ ) of the dissolution process. This behavior was not observed for physical mixtures (PMs) of both components. In this context, the material obtained was characterized for the dissolution rate of ABZ, and some mechanisms by which P 188 may act as an efficient carrier in SDs [10] were also explored. However, after an in vivo assessment in dogs, the drug plasma exposure of a suspension containing ABZ or ABZ formulated in a simple solid dispersion (capsules) was not significantly augmented [11]. The rise in the in vitro dissolution rate may have been attributed to an increase in the dissolution surface area, as well as an improvement in wettability and $A B Z$ solubilization as a consequence of carrier dissolution.

Any favorable effects of $\mathrm{P} 188$ are hidden by the gelation properties of this material as the temperature is raised [12]. In this way, when solid dispersions are placed in water at $37^{\circ} \mathrm{C}$, gel formation is expected [13-15] which may affect the kinetic release mainly due to the increase in viscosity. This fact becomes particularly evident when SDs are vehiculised into capsule, since compaction is produced as a consequence of the filling process [9]. It was clear that compaction played a central role in the potential effectiveness of DSs.

Furthermore, in previous work we have carried out a pharmacokinetic study in mice using multiparticulate (uncompacted) DSs and P188 as carrier. An increased systemic availability $(P<0.001)$ was obtained when ABZ was administered as ABZ-P 188 SDs, with a 50\% enhancement in systemic exposure (AUC values) compared to treatment with an ABZ suspension. Consistently, the Cmax increased 130\% $(P<0.001)$ following treatment with $\mathrm{P} 188$ based SD ABZ formulation [16]. In addition, the promising results concerning the potential effectiveness of SDs based on $\mathrm{P}$ 188 for improvement of $\mathrm{ABZ} \mathrm{Bd}$ and the utility of pharmacokinetic studies based on mice model for preliminary screen studies are worthy instead of using superior species (dogs).

Based on these observations, we hypothesize that the design of a solid dosage form with a much faster disintegration would prevent or at least minimize any deleterious gelation effects of $\mathrm{P} 188$ on the $\mathrm{ABZ}$ dissolution rate.

Currently, the design and development of rapidly disintegrating tablets (RDTs) is acquiring relevance due to the advantages of this system, such as easier swallowing and bioavailability improvement. The design of RDTs is based on the selection of adequate excipients which allow fast tablet disintegration (few seconds), even with very low amounts of water. The key properties of these tablets are the fast absorption or wetting of water into the tablets and the disintegration of associated particles into individual components for fast dissolution. This requires that excipients should have a high wettability and the tablet structure should also have a highly porous network. In order to achieve these objectives, conventional technologies have been addressed such as tablet molding, freeze drying, direct compression, granulation, and spray drying [17]. Likewise, innovative patented technologies have also been developed. Examples of these are Zydis, Orasolv, Durasolv, Wowtab, Ceform, Flashtab, Pharmaburst, Shearform, Ziplet, Oraquick, and Frosta [18].
In the present study we designed a formulation to use a marketed coprocessed excipient that had appropriate properties. In our case, we utilized Ludiflash as the main component of the formulae. This material is able to produce a very fast rupture of the tablet integrity after wetting, with consequent disintegration of the tablet into fine particles. In this context, the main objectives of this study were (a) to evaluate of the performance of the RDTs as a way to improve the SDs in vitro and (b) to study the in vivo pharmacokinetics of this ABZ modified formulation in dogs.

\section{Materials and Methods}

2.1. In Vitro Assessment: Materials. The following materials were used for the preparation of the solid dispersions: ABZ (Pharmaceutical grade, Parafarm, Buenos Aires, Argentina) POLOXAMER 188 (BASF, Germany). All other reagents were of analytical grade.

For the preparation of tablets, the following excipients were used: lactose, microcrystalline cellulose, sodium crosscarmellose, colloidal silicon dioxide, magnesium stearate (Parafarm, Buenos Aires, Argentina), and Ludiflash (BASF, Ludwigshafen, Germany).

\subsection{Methods}

2.2.1. Preparation of Solid Dispersions. SDs were prepared by melting the carrier ( $\mathrm{P} 188)$ at $63^{\circ} \mathrm{C}$ and with posterior dispersion of $\mathrm{ABZ}$ at $50 \% \mathrm{w} / \mathrm{w}$. The mixtures were homogenized by stirring during heating and dispersion. Then, the semisolid dispersion was rapidly cooled and pulverized. The 212-micron particle size fraction was obtained by sieving and was maintained $\left(8^{\circ} \mathrm{C}\right)$ in a screw-capped glass vial until use.

2.2.2. Development of Solid Dosage Form. The blend of powders was compressed for $5 \mathrm{~s}$ in a hydraulic press (Delfabro, Argentina) at 1000, 1500, and $2000 \mathrm{mPa}$ for conventional tablets (CTs) and at 250, 500, and $1000 \mathrm{mPa}$ for RDTs with $13.0 \mathrm{~mm}$ flat punches. Tablet hardness was measured on recently prepared tablets using an electronic hardness tester (AVIC, Argentina). Two tablets formulations (Table 1) containing $200 \mathrm{mg}$ of the drug were prepared by direct compression, with the tableting process, as well as subsequent storage of the RDT and CTs, taking place in a conditioned room at $21^{\circ} \mathrm{C}$ and $45 \% \mathrm{RH}$.

\subsubsection{Physical Mechanical Properties}

Density and Compressibility. To determine the density of the powdered blends, the material was gently poured into a $10 \mathrm{~cm}^{3}$ graduate cylinder, with bulk density (BD) being calculated as the ratio between the weight ( $\mathrm{g}$ ) and volume $\left(\mathrm{cm}^{3}\right)$. To determine the ultimate tap density (TD), the cylinder was tapped over a 1.0-inch vertical drop, at $1 \mathrm{~s}$ interval, until no measurable change in volume was noticed. The compressibility of the powder was evaluated using 
TABLE 1: Components of the rapidly disintegrating tablets (RDTs) and conventional tablets (CTs).

\begin{tabular}{lcc}
\hline Ingredients (mg) & $\begin{array}{c}\text { Rapidly disintegrating } \\
\text { tablets }\end{array}$ & $\begin{array}{c}\text { Conventional } \\
\text { tablets }\end{array}$ \\
\hline Albendazole & - & 200 \\
Solid dispersions & 400 & - \\
Lactose/Avicel & - & $25 / 75$ \\
Ludiflash & 732 & - \\
Sodium crosscarmellose & 60 & 67.2 \\
Colloidal silicon dioxide & - & 8 \\
Magnesium stearate & 8 & 16 \\
\hline
\end{tabular}

the Hausner ratio (HR) and Carr's index (CI) [19] according to the following equations:

$$
\begin{gathered}
\mathrm{HR}=\frac{\mathrm{TD}}{\mathrm{BD}}, \\
\mathrm{CI}=\frac{\mathrm{TD}-\mathrm{BD}}{\mathrm{TD}} \times 100 .
\end{gathered}
$$

Angle of Repose ( $\alpha$ ). The dynamic $\alpha$ for each mixture of powders was determined by the funnel method as described in the literature [20].

2.2.4. Dissolution Test. Dissolution tests of RDTs and CTs were performed using USPXXIV dissolution apparatus 2 (SOTAX AT 7 smart). The rotational paddle speed was set at $50 \mathrm{rpm}$, and the temperature remained constant at $37 \pm$ $0.5^{\circ} \mathrm{C}$. The assayed amount of $\mathrm{ABZ}$ was $200 \mathrm{mg}$ per tablet for all experiments.

As dissolution medium of $900 \mathrm{~mL} 0.1 \mathrm{~N} \mathrm{HCl}$ solution was used, five-milliliter aliquots were withdrawn at predetermined time intervals during $1 \mathrm{~h}$, and the same amount of fresh medium was added in order to keep the volume constant throughout the test. The samples were filtered, and the concentration of dissolved drug was measured at $297 \mathrm{~nm}$ using a UV-vis spectrophotometer (Termo Evolution 300).

All measurements were performed in triplicate. In a previous test, we verified that the presence of carriers dissolved in the dissolution medium did not affect the $\lambda_{\max }$ of ABZ. The percentages of dissolved drug were statistically analyzed by a one-way analysis of variance. Differences were considered statistically significant at $P<0.05$.

\subsubsection{In Vivo Assessment: Pharmacokinetic Study}

(1) Experimental Animals. Six healthy (3-6-year-old) parasite-free female Retriever dogs, weighing $25-35 \mathrm{Kg}$, were used in this trial. Whole dogs were fed $12 \mathrm{~h}$ before the treatment and refed $12 \mathrm{~h}$ upon treatment. Experimental dogs were randomly allocated into two groups $(n=3)$ (group I: animals number 1 , number 2 , number 3 ; group II: animals number 4 , number 5, number 6), which received two different treatments using a crossover design. Each experimental treatment was given to the six animals in two phases: phase I: animals in Group I received ABZ at $25 \mathrm{mg} / \mathrm{kg}$ as CTs (treatment A). Animals in Group II received $25 \mathrm{mg} / \mathrm{kg}$ of ABZ vehiculized in RDT (treatment B). After 21 days of a washout period, both treatments were reversed and repeated as phase II.

Blood samples were collected from the antebrachial vein using a $18 \mathrm{G}$ catheter before administration (time 0 ) and at $0.25,0.5,1,2,4,8,12,18$, and $24 \mathrm{~h}$ after the oral administrations of the respective formulations, before being immediately transferred into heparinized tubes. Blood samples were centrifuged at $2000 \times \mathrm{g}$ for $15 \mathrm{~min}$ and the recovered plasma was stored at $-20^{\circ} \mathrm{C}$ until analysis by HPLC.

(2) Analysis of ABZ and Its Metabolites. Sample cleanup: ABZ, $\mathrm{ABZSO}$, and $\mathrm{ABZSO}_{2}$ were extracted using disposable $\mathrm{C18}$ columns. Five microliters of Oxfendazole (OBZ) $(5 \mu \mathrm{g} / \mathrm{mL})$ was added to $100 \mu \mathrm{L}$ of plasma in a glass test tube. Spiked samples were placed into a $\mathrm{Cl} 8$ column preconditioned with $0.5 \mathrm{~mL}$ of methanol followed by $0.5 \mathrm{~mL}$ water, in a vacuum system. Samples were washed ( $2 \mathrm{~mL}$ of water) and then eluted with $2 \mathrm{~mL}$ of HPLC-grade methanol. After elution, all samples were concentrated to dryness in a vacuum concentrator and then reconstituted with $150 \mu \mathrm{L}$ of the mobile phase.

HPLC Analysis. Experimental and spiked plasma samples (used for validation) were analysed by HPLC using UV detection.

Chromatography was performed on a Shimadzu HPLC equipment (Shimadzu Corporation, Kyoto, Japan), provided with two LC-10AS solvent pumps, an automatic sample injector (SIL-10A) with a $50 \mu \mathrm{L}$ loop, an ultraviolet visible spectrophotometric detector (UV) (SPD-10A) read at 292 $\mathrm{nm}$, a column oven (Eppendorf TC-45, Eppendorf, Madison, WI, USA) set at $30^{\circ} \mathrm{C}$, and a CBM-10A integrator. Data and chromatograms were collected and analyzed using the Class LC10 software (SPD-10A, Shimadzu Corporation, Kyoto, Japan). The C18 reversed-phase column $(5 \mu \mathrm{m}, 250 \mathrm{~mm} \times$ $4.6 \mathrm{~mm}$ ) was obtained from Kromasil (Kromasil, Sweden). Elution from the stationary phase was carried out at a flow rate of $1.2 \mathrm{~mL} / \mathrm{min}$ using acetonitrile (40\%) and a potassium phosphate buffer ( $25 \mathrm{mM}$, pH 5.3, 40\%) as the mobile phase.

Fifty microliters of each sample was injected, and the analytes were eluted from the analytical column $(5 \mu \mathrm{m}$, $250 \mathrm{~mm} \times 4.6 \mathrm{~mm}, \mathrm{C} 18$ column) using a linear gradient method as reported by Sánchez et al. [21]. The compounds were identified by the retention times of standard references. Plasma calibration curves for each analyte were constructed by a least squares linear regression analysis, which gave a correlation coefficient $(r)$ of between 0.9987 and 0.9995 . The limits of quantification were $0.01 \mu \mathrm{g} / \mathrm{mL}$ (ABZ and ABZSO) and $0.03 \mu \mathrm{g} / \mathrm{mL}\left(\mathrm{ABZSO}_{2}\right)$.

Pharmacokinetic Analysis of the Data. The concentration versus time curves for the metabolites $\mathrm{ABZSO}$ and $\mathrm{ABZSO}_{2}$ in plasma for each individual animal after the different treatments were fitted using PK Solution 2.0 (Summit research services, Ashland, OH, USA). The following equation [22] was used to describe the biexponential concentration-time curves for $\mathrm{ABZSO}$ and $\mathrm{ABZSO}_{2}$ after the oral treatment:

$$
C_{p}=B e^{-\lambda_{2} \cdot t}-B e^{-\lambda_{1} \cdot t}
$$


TABLE 2: Physical-mechanical characterization of the formulations: Bulk density (BD), Tap density (TD), Carr's index, Hausner ratio, and angle of repose.

\begin{tabular}{|c|c|c|c|c|c|}
\hline & Angle of repose $\left(^{\circ}\right)$ & Carr's index (\%) & Hausner Ratio (\%) & $\mathrm{TD}(\mathrm{m} / \mathrm{v})$ & $\mathrm{BD}(\mathrm{m} / \mathrm{v})$ \\
\hline Conventional tablets & $39 \pm 2$ & 16.6 & 1.2 & $0.6 \pm 0.02$ & $0.5 \pm 0.1$ \\
\hline Rapidly disintegrating tablets & $38.9 \pm 1.65$ & 22.22 & 1.28 & $0.63 \pm 0.02$ & $0.49 \pm 0.01$ \\
\hline
\end{tabular}

TABLE 3: Values of hardness and disintegration time for both formulations at different compaction forces.

\begin{tabular}{lccr}
\hline & Compaction force $(\mathrm{mPa})$ & Hardness $\left(\mathrm{kg} / \mathrm{cm}^{2}\right)$ & Disintegration time $(\mathrm{min})$. \\
\hline \multirow{3}{*}{ Conventional tablets } & 1000 & $4 \pm 1$ & 5.5 \\
& 1500 & $11 \pm 1$ & 12 \\
\hline \multirow{3}{*}{ Rapidly disintegrating tablets } & 2000 & $18 \pm 3$ & 15 \\
& 250 & $3 \pm 0.5$ & 2.5 \\
& 500 & $8 \pm 0.5$ & 2.5 \\
\hline
\end{tabular}

where $C_{p}$ is concentration in plasma at time $t$ after administration $(\mu \mathrm{g} / \mathrm{mL}) ; B$ is concentration at time zero, extrapolated from the elimination phase $(\mu \mathrm{g} / \mathrm{mL}) ; e$ is base of the natural logarithm; $\lambda_{2}$ is terminal slope $\left(\mathrm{h}^{-1}\right)$; and $\lambda_{1}$ is the slope obtained by feathering, which represents either the first-order absorption rate constant $\left(\lambda_{1}\right)$ or the first-order metabolite formation rate constant $\left(\lambda_{\text {for }}\right)\left(\mathrm{h}^{-1}\right)$. The elimination half-life $\left(t_{1 / 2} \lambda_{2}\right)$ and absorption $\left(t_{1 / 2} \lambda_{1}\right)$ or the metabolite formation half-lives $\left(t_{1 / 2} \lambda_{\text {for }}\right)$ were calculated as $\ln 2 / \lambda_{2}$ and $\ln 2 / \lambda_{1}$, respectively.

The peak concentration $\left(C_{\max }\right)$ and time to peak concentration $\left(T_{\max }\right)$ were obtained from the plotted concentrationtime curve of each analyte. The area under the concentrationtime curve (AUC) and the area under the first moment curve (AUMC) were calculated by the linear trapezoidal rule [23]:

$\operatorname{AUMC}_{(0-\infty)}=\sum_{i=0}^{n-1} \frac{t_{i+1}-t_{i}}{2}\left(c_{i} t_{i}+c_{i+1} t_{i+1}\right)\left(\frac{C_{\text {last }} * t_{\text {last }}}{\lambda_{z}}+\frac{C_{\text {last }}}{\lambda_{z}^{2}}\right)$

Statistical Analysis of the Data. The nonparametric MannWhitney test was used for the multiple statistical comparisons of the PK data obtained from the different groups. A value of $P<0.05$ was considered to be statistically significant.

\section{Results and Discussion}

Powder blends easily compacted by means of direct compression should possess good flow and compression properties. The rheological properties of powder blends were assayed by evaluation of density, angle of repose, and compressibility (Hausner ratio). The Hausner ratio and Carr's index refer to the packing characteristics of the materials and therefore can be used as indicators of powder flowability. For both RDT and CT formulations, the results (Table 2) showed that the powders possessed suitable rheological properties and compressibility. The hardness, disintegration, and friability of the compacts were also evaluated for each formulation
(Table 3) because tablet disintegration as well as drug dissolution is relevant, with both being closely related to the expected biopharmaceutical performance of the formulation. As expected, the disintegration time was shorter in the case of RDTs in comparison to the CTs. This may have been attributed to the incorporation of Ludiflash into the formulae, which was then able to produce water uptake, swelling, and quick rupture of the compact. For both formulations and for all the compaction forces, the friability was less than $1 \%$.

Regarding the compression behaviour, the influence of compaction forces (CF) on the hardness and the disintegration time of the compact was analysed. When the CF was raised, an increase of the hardness in the tablets was observed, as expected. This was remarkable when CTs were considered, due to the presence of Avicel, which is a very compressible material.

The in vitro ABZ dissolution profiles are shown in Figures 1(a) and 1(b). In particular the RDTs dissolution rate was not affected by increasing the $\mathrm{CF}$, when tablets were compacted at 250 and $500 \mathrm{mPa}$. However, at $1000 \mathrm{mPa}$ a slower dissolution rate was visualized, which was a consequence of the observed enhancement of the disintegration time. The CTs compacted at $1000 \mathrm{MPa}$ showed the fastest dissolution rate, as observed in Figure 1(b).

From these results, and based on the lower hardness/disintegration and faster dissolution rate, CTs compacted at $1000 \mathrm{mPa}$ and RDTs compacted at $500 \mathrm{mPa}$ were selected as the model formulations for further in vivo bioavailability studies.

Differences in the pharmacokinetic profiles of benzimidazoles (BZD) anthelmintics have been reported, depending on the animal species. Anatomic features influence the passage of digesta and the bioavailability, so the pharmacokinetics of anthelmintics may be affected by different gut transit features [24]. ABZ parent drug was not detected in plasma, being the detection of the metabolite ABZSO (also named ricobendazole) as the main molecule with antiparasitic activity in bloodstream. In dogs, the plasma concentrations and the mean residence times of $\mathrm{ABZ}$ and their sulfoxide and 


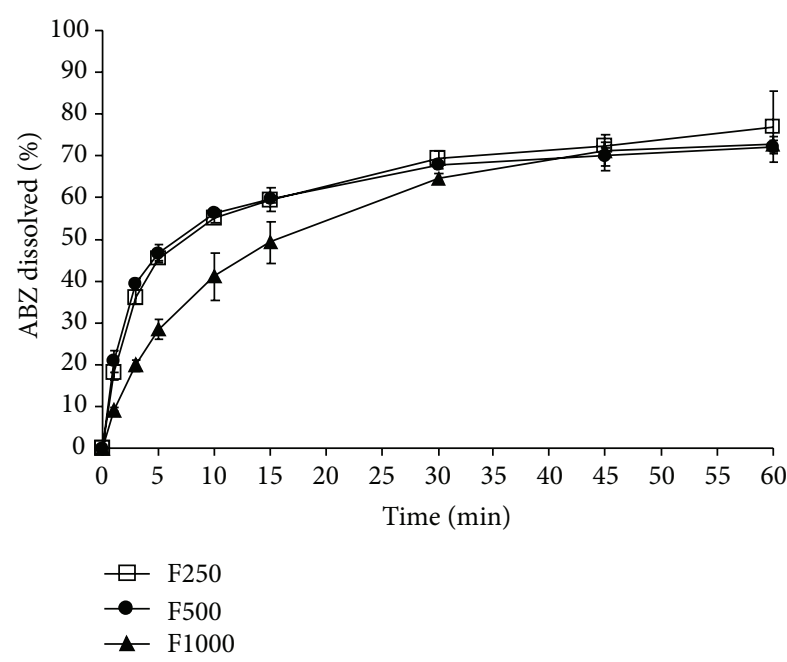

(a)

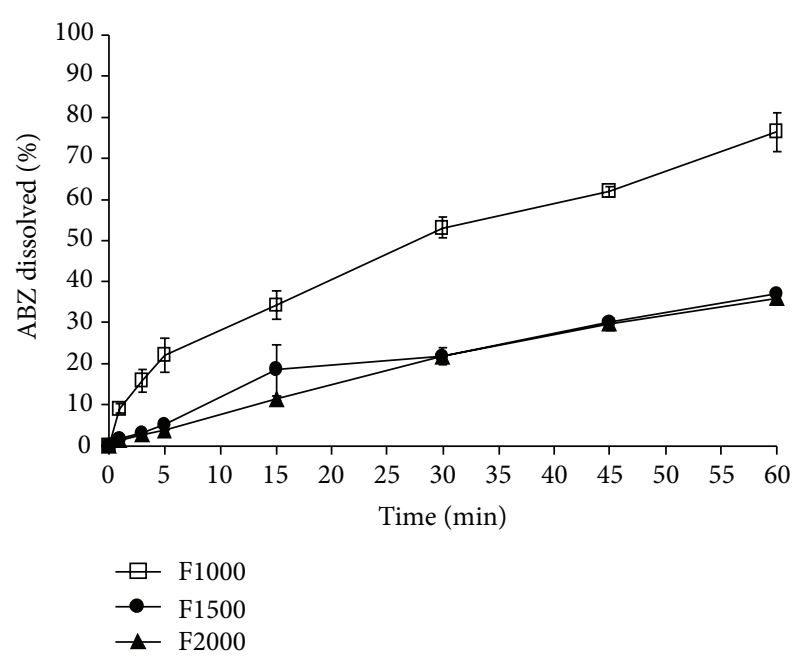

(b)

Figure 1: Dissolution profile: (a) rapidly disintegrating tablets (RDTs) and (b) conventional tablets (CTs) at different compaction forces: F250: compaction forces a $250 \mathrm{mPa}$; F500: compaction forces a $500 \mathrm{mPa}$; F1000: compaction forces a $1000 \mathrm{mPa}$; F1500: compaction forces a $1500 \mathrm{mPa}$; F2000: compaction forces a $2000 \mathrm{mPa}$.

sulphone metabolites are lower and shorter, respectively, in comparison to in ruminant species on human [25]. This may be explained by the fact that there exists a relatively short transit time in the gastrointestinal tract of dogs compared to other animal species.

According to various reports, the absorption of BZD anthelmintic drugs in cats, dogs, and humans is substantially limited by their low dissolution rates in gastric fluids [26, 27]. Consequently, these compounds must be administrated at high doses or as multiple doses in order to provide sustained concentrations at the parasite site. It is well known that the incorporation of low-solubility drugs into solid dispersions (SDs) is an effective alternative for increasing the in vitro dissolution rate. In this paper, we improved this property in $\mathrm{ABZ}$ by obtaining a solid dispersion compounded by ABZ:P 188 (1:1) [8], with an increase being observed in the dissolution assays when solid dispersions were poured as powder onto the dissolution media surface. However, when SDs were put into capsules, the corresponding dissolution test showed that the capsules were not able to improve the dissolution rate [9].

As a consequence of the thermal gelation properties of P 188, the partially compacted powder absorbed water produced swelling and gel formation and an increase in gel viscosity due to the rise of temperature $\left(37^{\circ} \mathrm{C}\right)$. However, this behavior was practically negligible when SDs were manipulated as a bulk powder in similar conditions. In a previous work, carried out on mice, we observed a significant increase in the bioavailability when solid dispersions were administered orally as a multiparticulate system (thus avoiding the effects of compaction) compared to ABZ suspension [28].

From these results and considering that the formulation of a tablet may imply a compaction process that decisively affects the dissolution rate, we investigated the incorporation of $\mathrm{ABZ}$ solid dispersion in the RDTs (treatment $\mathrm{B}$ ), as a viable alternative for avoiding or minimizing adverse effects. Therefore, the formulation with ABZ incorporated in CTs (treatment A) was studied for its effect on the bioavailability in dogs (Figures 2 and 3, Table 4).

In our case, the results obtained in vitro were reflected in the in vivo studies.

As reported in other studies, after both treatments the ABZ parent drug was not detected in the plasma, but ABZSO was detected in plasma at $18 \mathrm{~h}$ and $24 \mathrm{~h}$ after treatment (treatments $\mathrm{A}$ and $\mathrm{B}$, respectively). This ABZSO plasma disposition (AUC) was significantly greater (1.6-fold more at $P<0.05)$ after treatment $\mathrm{B}$ compared to treatment $\mathrm{A}$. This same trend was observed for parameter $C_{\max }$ after treatment $\mathrm{B}$, where the concentration obtained was 1.5 -fold higher compared with treatment A $(P<0.05)$. A nonsignificant delay in $T_{\text {max. }}$ was present after treatment B $(7.2 \mathrm{~h})$ compared with treatment A (6 h) (see Table 4 and Figure 2).

Modifications of the pharmacokinetic parameters were reflected in an improvement of the dissolution rate as a consequence of the rapid disintegration of the RDTs, which produced a remarkable increase in kinetic absorption as well as in the drug amount available in the plasma. The RDTs were able to disintegrate in only a few seconds after administration, allowing the resulting fine solid dispersion to reach the stomach where the rapid dissolution of solids may occur. In contrast, each solid particle compacted in CTs was very difficult to be accessed by the solvent, and a process of swelling and gelation began. Thus, the gel layer formed prevented the particle from being wetted and resulted in disintegration and drug dissolution. This delay in the ABZ dissolution process was especially deleterious for ABZ bioavailability, since it has to dissolve rapidly along the short length of the dog's gastrointestinal tract. 
TABLE 4: Comparative plasma disposition kinetic variables for albendazole sulfoxide $(\mathrm{ABZSO})$ and albendazole sulphone $\left(\mathrm{ABZSO}_{2}\right)$ after the oral administration of three different formulations.

\begin{tabular}{|c|c|c|c|c|}
\hline \multirow{2}{*}{ Pk parameters } & \multicolumn{2}{|c|}{ Group I (ABZ control) conventional tablets } & \multicolumn{2}{|c|}{ Group II Rapidly disintegrating tablets } \\
\hline & ABZSO & $\mathrm{ABZSO}_{2}$ & ABZSO & $\mathrm{ABZSO}_{2}$ \\
\hline$T_{1 / 2 \text { abs. }}(\mathrm{h})$ & $2.14 \pm 1.28$ & $2.46 \pm 1.81$ & $2.38 \pm 0.42$ & $4.93 \pm 1.81$ \\
\hline$T_{\max }(\mathrm{h})$ & $6.00 \pm 2.31$ & $7.13 \pm 4.80$ & $7.20 \pm 1.79$ & $12 \pm 0.00$ \\
\hline$T_{1 / 2 \text { elim. }}(\mathrm{h})$ & $4.67 \pm 1.68$ & $32.13 \pm 39.63$ & $4.73 \pm 1.19$ & $10.86 \pm 7.47$ \\
\hline$C_{\max }(\mu \mathrm{g} / \mathrm{mL})$ & $5.33 \pm 2.83$ & $0.67 \pm 0.27$ & $8.18^{*} \pm 1.47$ & $1.13 \pm 0.34$ \\
\hline $\mathrm{AUC}_{0-\infty}(\mu \mathrm{g} \cdot \mathrm{h} / \mathrm{mL})$ & $52.20 \pm 12.95$ & $33.32 \pm 46.20$ & $113.11^{*} \pm 22.85$ & $22.32 \pm 10.33$ \\
\hline $\operatorname{AUMC}_{0-\infty}\left(\mu \mathrm{g} \cdot \mathrm{h}^{2} / \mathrm{mL}\right)$ & $718.50 \pm 274.17$ & $222.56 \pm 149.04$ & $1180.30 \pm 306.44$ & $382.18 \pm 344.47$ \\
\hline MRT (hr) & $12.11 \pm 3.99$ & $49.76 \pm 56.09$ & $10.48 \pm 1.78$ & $21.71 \pm 10.90$ \\
\hline PDP $(\mathrm{h})$ & $0.25-24.0$ & $0.25-24.00$ & $0.25-24.0$ & $0.25-24.0$ \\
\hline
\end{tabular}

$T_{1 / 2}$ abs. metabolite formation half-life, $C_{\max }$ : peak concentration, $T_{\max }$ : time at $C_{\max }, T_{1 / 2}$ elim. elimination half life, $\mathrm{AUC}_{0-\infty}$ : area under the concentration versus time curve extrapolated to infinity, $\mathrm{AUMC}_{0-\infty}$ : area under the moment of the concentration versus time curve extrapolated to infinity, MRT: Mean residence time, and PDP: plasma detection period. $\left({ }^{*}\right)$ values are statistically different to group I at $P<0.05$.

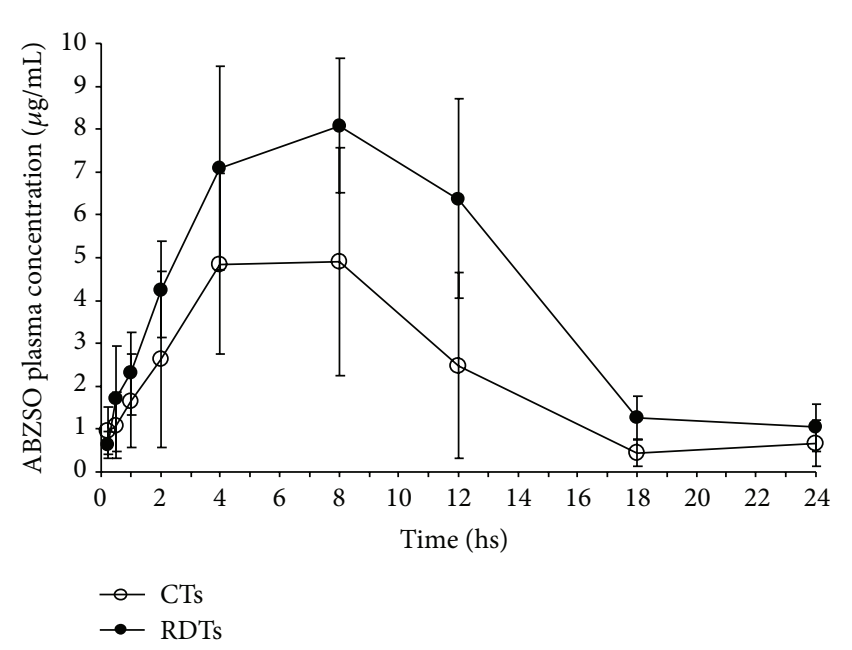

Figure 2: Comparative (mean $\pm \mathrm{SD}$ ) plasma profiles for albendazole sulfoxide (ABZSO) after the administration of two different oral-based albendazole (ABZ) formulations: rapidly disintegrating tablets (RDTs) and conventional tablets (CTs).

\section{Conclusions}

The bioavailability of ABZ from SD compacted in tablets was extremely conditioned by the initial dissolution rate. A tablet design based on fast disintegrating excipients was shown to be more successful in increasing the absorption process compared with traditional tablets. Therefore, rapid disintegration of tablets seems to be a key factor for efficiency of SD with regard to improvement of the ABZ bioavailability.

The in vivo assays performed on dogs showed a marked increase in drug plasma exposure when $\mathrm{ABZ}$ was given in $\mathrm{SD}$ incorporated into RDTs compared with CTs. This behavior allowed us to deduce that a positive and direct correlation existed between the in vitro dissolution rate and the expected pharmacokinetic of ABZ. Although SD was demonstrated to be an efficient strategy for improving the dissolution rate, a correct formulation of the tablet was necessary in order to guarantee that the disintegration process was not a limiting step in the ABZ absorption. This formulation may have

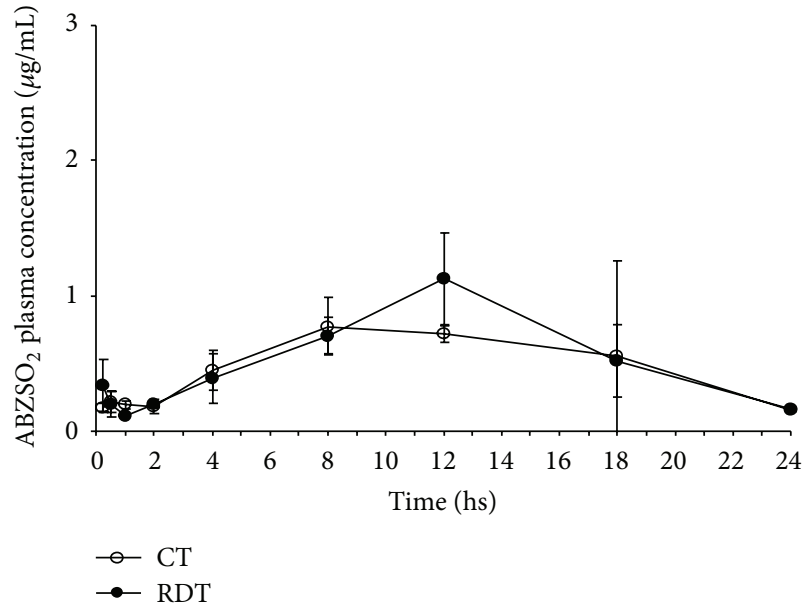

FIGURE 3: Comparative (mean $\pm \mathrm{SD}$ ) plasma profiles for albendazole sulphone $\left(\mathrm{ABZSO}_{2}\right)$ after the administration of two different oral-based albendazole (ABZ) formulations: rapidly disintegrating tablets (RDTs) and conventional tablets (CTs).

a beneficial impact by shortening the antiparasite therapy time needed in monogastrics.

\section{Appendix}

Animal procedures and management protocols were approved by the Ethics Committee according to the Animal Welfare Policy (act 087/02) of the Faculty of Veterinary Medicine, Universidad Nacional del Centro de la Provincia de Buenos Aires (UNCPBA), Tandil, Argentina (http://www .vet.unicen.edu.ar/).

\section{Acknowledgments}

The authors express their gratitude for the financial support granted by the Consejo Nacional de Investigaciones Científicas y Técnicas (CONICET), the Agencia Nacional de Promoción Científica y Tecnológica (ANPCyT), and 
the Universidad Nacional de Córdoba (UNC) of Argentina. The authors thank the invaluable support of the people of the Uruguayan Navy Army (Narcotic Division), for providing the animals for this trial. The authors also thank Laboratorio UNIMEDICAL Uruguay for the donation of antiparasitic drugs.

\section{References}

[1] M. Murray, A. M. Hudson, and V. Yassa, "Hepatic microsomal metabolism of the anthelmintic benzimidazole fenbendazole: enhanced inhibition of cytochrome $\mathrm{P} 450$ reactions by oxidized metabolites of the drug," Chemical Research in Toxicology, vol. 5, no. 1, pp. 60-66, 1992.

[2] C. E. Lanusse and R. K. Prichard, "Clinical pharmacokinetics and metabolism of benzimidazole anthelmintics in ruminants," Drug Metabolism Reviews, vol. 25, no. 3, pp. 235-279, 1993.

[3] D. E. Jacobs, "Anthelmintics for dogs and cats," International Journal for Parasitology, vol. 17, no. 2, pp. 511-518, 1987.

[4] E. L. Roberson and T. M. Burke, "Evaluation of granulated fenbenazole as a treatment for helminth infections in dogs," Journal of the American Veterinary Medical Association, vol. 180, no. 1, pp. 53-55, 1982.

[5] G. Edwards and B. Breckenridge, "Clinical pharmacokinetics of anthelmintic drugs," Clinical Pharmacokinetics, vol. 15, no. 2, pp. 67-93, 1988.

[6] G. L. Amidon, H. Lennernas, V. P. Shah, and J. R. Crison, "A theoretical basis for a biopharmaceutic drug classification: the correlation of in vitro drug product dissolution and in vivo bioavailability," Pharmaceutical Research, vol. 12, no. 3, pp. 413420, 1995.

[7] H. R. Wen, R. R. C. New, and P. S. Craig, "Diagnosis and treatment of human hydatidosis," British Journal of Clinical Pharmacology, vol. 35, no. 6, pp. 565-574, 1993.

[8] A. A. Noyes and W. R. Whitney, "The rate of solution of solid substances in their own solutions," The Journal of the American Chemical Society, vol. 19, no. 12, pp. 930-934, 1897.

[9] K. Sekiguchi and N. Obi, "Studies on absorption of eutectic mixtures. I. A comparison of the behavior of eutectic mixtures of sulphathiazole and that of ordinary sulphathiazole in man," Chemical \& Pharmaceutical Bulletin, vol. 9, no. 11, pp. 866-872, 1961.

[10] S. G. Castro, S. S. Bruni, C. E. Lanusse, D. A. Allemandi, and S. D. Palma, "Improved albendazole dissolution rate in pluronic 188 solid dispersions," AAPS PharmSciTech, vol. 11, no. 4, pp. 1518-1525, 2010.

[11] A. Dib, S. Palma, G. Suárez et al., "Albendazole sulphoxide kinetic disposition after treatment with different formulations in dogs," Journal of Veterinary Pharmacology and Therapeutics, vol. 34, no. 2, pp. 136-141, 2011.

[12] B. K. Nanjawade, F. V. Manvi, and A. S. Manjappa, "In situforming hydrogels for sustained ophthalmic drug delivery," Journal of Controlled Release, vol. 122, no. 2, pp. 119-134, 2007.

[13] N. A. Peppas and J. J. Sahlin, "A simple equation for the description of solute release. III. Coupling of diffusion and relaxation," International Journal of Pharmaceutics, vol. 57, no. 2, pp. 169-172, 1989.

[14] P. L. Ritger and N. A. Peppas, "A simple equation for description of solute release II. Fickian and anomalous release from swellable devices," Journal of Controlled Release, vol. 5, no. 1, pp. 37-42, 1987.
[15] P. L. Ritger and N. A. Peppas, "A simple equation for description of solute release II. Fickian and anomalous release from swellable devices," Journal of Controlled Release, vol. 5, no. 1, pp. 37-42, 1987.

[16] S. G. Castro, S. F. S. Bruni, L. P. Urbizu, A. Confalonieri, L. Ceballos, and C. E. Lanusse, "Allemandi DA and PalmalSA. Enhanced dissolution and systemic availability of albendazole formulated as solid dispersions," Pharmaceutical Development and Technology, vol. 18, no. 2, pp. 434-442, 2013.

[17] S. Shaikh, R. V. Khirsagar, and A. Quazi, "Fast disintegrating tablets: an overview of formulation and technology," International Journal of Pharmacy and Pharmaceutical Sciences, vol. 2, no. 3, pp. 9-15, 2010.

[18] T. K. Giri, D. K. Tripathi, and R. Majumdar, "Formulation aspects in the development of orodispersible tablets: an overview," International Journal of Pharmacy and Pharmaceutical Sciences, vol. 2, no. 3, pp. 38-42, 2010.

[19] P. C. Schmidt and C. J. W. Rubensdorfer, "Evaluation of Ludipress as a 'multipurpose excipient' for direct compression. Part I: powder characteristics and tableting properties," Drug Development and Industrial Pharmacy, vol. 20, no. 18, pp. 28992925, 1994.

[20] R. J. Lantz and J. B. Schwartz, "Mixing," in Pharmaceutical Dosage Form: Tablets, H. A. Lieberman, L. Lachman, and J. B. Schwartz, Eds., vol. 2, Marcel Dekker, New York, NY, USA, 1990.

[21] S. F. Sánchez, L. I. Alvarez, and C. E. Lanusse, "Nutritional condition affects the disposition kinetics of albendazole in cattle," Xenobiotica, vol. 26, no. 3, pp. 307-320, 1996.

[22] R. E. Notari, "Pharmacokinetics", in Biopharmaceutics and Clinical Pharmacokinetics, R. E. Notari, Ed., pp. 45-128, Marcel Dekker, New York, NY, USA, 4th edition, 1987.

[23] M. Gibali and D. Perrier, Pharmacokinetics, Marcel Dekker, New York, NY, USA, 2nd edition, 1982.

[24] Q. A. McKellar and E. W. Scott, "The benzimidazole anthelmintic agents-a review," Journal of veterinary pharmacology and therapeutics, vol. 13, no. 3, pp. 223-247, 1990.

[25] C. Gokbulut, A. Bilgili, B. Hanedan, and Q. A. McKellar, "Comparative plasma disposition of fenbendazole, oxfendazole and albendazole in dogs," Veterinary Parasitology, vol. 148, no. 3-4, pp. 279-287, 2007.

[26] E. L. Roberson and T. M. Burke, "Evaluation of granulated fenbenazole as a treatment for helminth infections in dogs," Journal of the American Veterinary Medical Association, vol. 180, no. 1, pp. 53-55, 1982.

[27] G. Edwards and B. Breckenridge, "Clinical pharmacokinetics of anthelmintic drugs," Clinical Pharmacokinetics, vol. 15, no. 2, pp. 67-93, 1988.

[28] S. G. Castro, S. D. Palma, D. A. Allemandi et al., "Development of alternative Albendazole pharmaceutical preparations," in Proceedings of the 23rd International Conference of the World Association for the Advancement of Veterinary Parasitology, Buenos Aires, Argentina, 2011. 

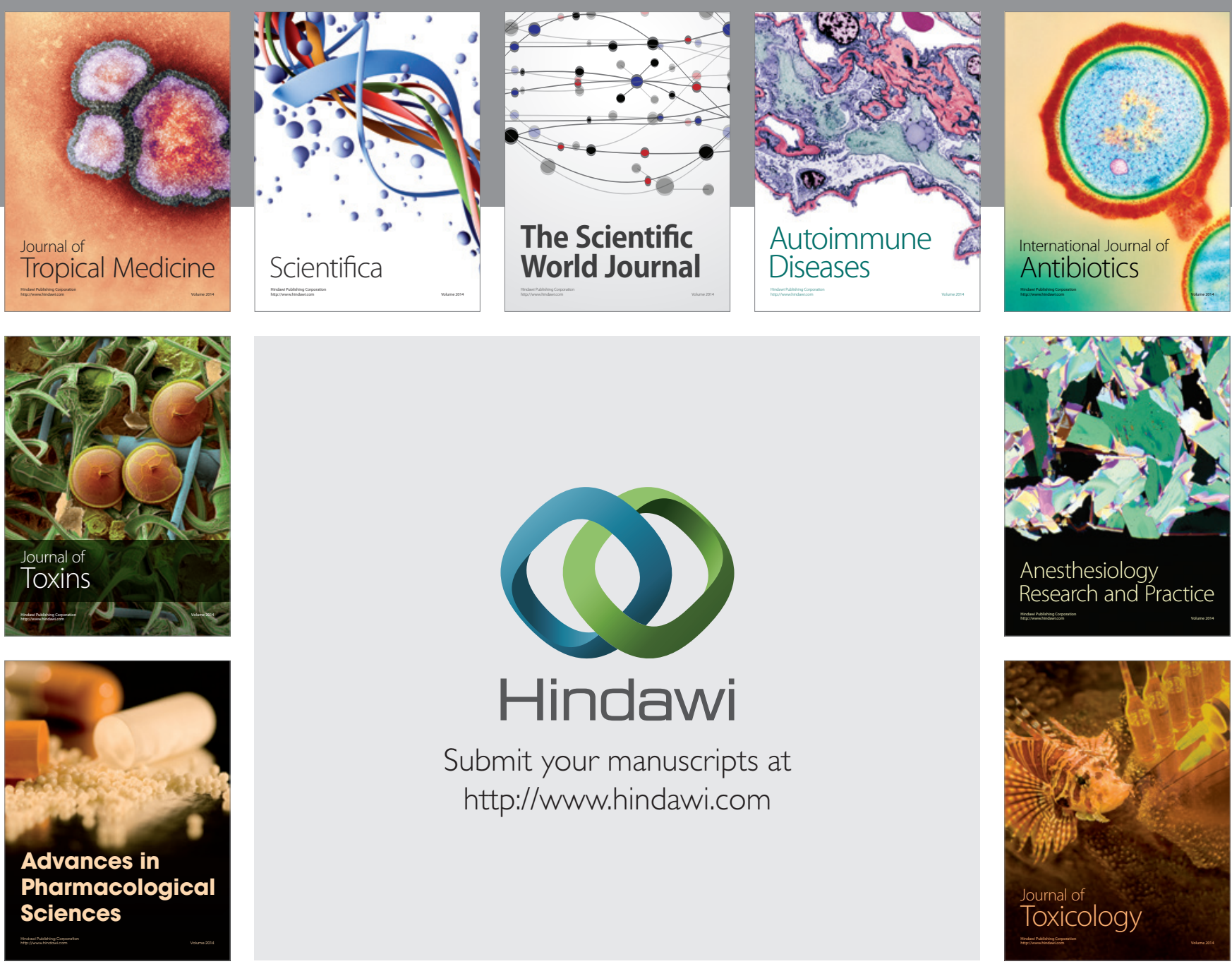

\section{Hindawi}

Submit your manuscripts at

http://www.hindawi.com
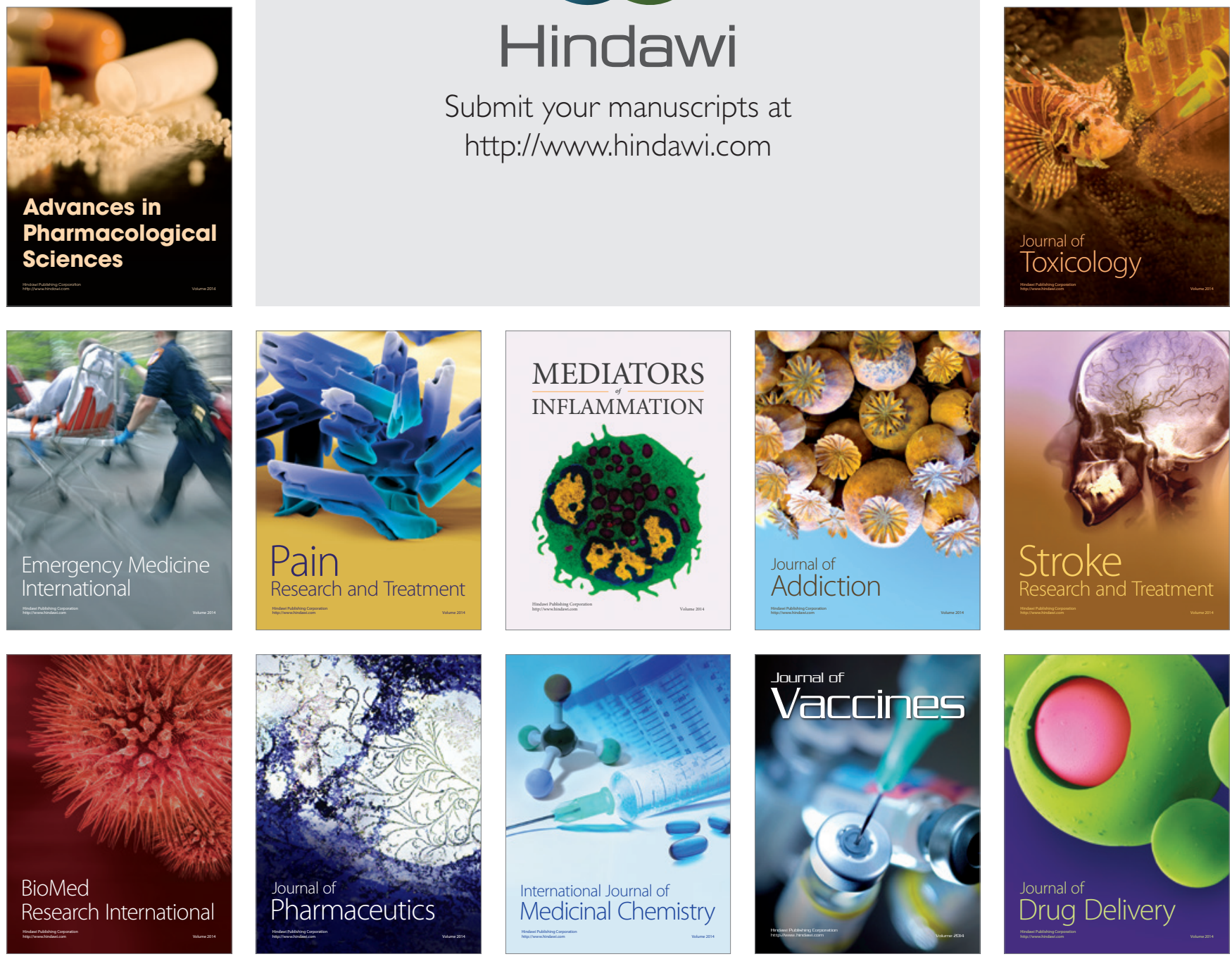